\title{
Sacral Giant Cell Tumor-Induced Cauda Equina Syndrome: Case Report with Successful Management
}

\author{
Saraj K. Singh ${ }^{1}$ Avinash Kumar ${ }^{2}$ Jitendra Nigam³,๑ \\ 1Department of Neurosurgery, All India Institute of Medical \\ Sciences, Patna, Bihar, India \\ 2Department of Orthopedics, All India Institute of Medical Sciences, \\ Patna, Bihar, India \\ ${ }^{3}$ Department of Pathology, All India Institute of Medical Sciences, \\ Patna, Bihar, India
}

\begin{abstract}
Address for correspondence Saraj Kumar Singh, MS, MCh, Department of Neurosurgery, All India Institute of Medical Sciences, Patna 801507, Bihar, India (e-mail: dr.sarajkumarsingh@gmail.com).
\end{abstract}

J Neurosci Rural Pract 2021;12:398-401.

\begin{abstract}
Sacral giant cell tumor (GCT) is a rare entity. It often presents late after massive enlargement of tumor. Here we are reporting a case of sacral GCT treated successfully at our institute. A 30-year-old male patient presented with paraplegia, significant sensory disturbance below L2 level, along with severe vesicorectal dysfunction. On imaging, giant mass was seen filling the sacrum with homogenous enhancement and

Keywords

- sacral giant cell tumor

- lumboiliac fixation

- cauda equina

syndrome

flow voids from L5 level to S4 level. The patient underwent surgical exploration with L4-5 decompressive laminectomy, near-total resection of tumor, and lumboiliac fixation. The patient recovered symptomatically in postoperative period. Sacral GCT is a rare but treatable lesion. Its presentation as sudden cauda equina syndrome is rare, but final management should be aggressive with en bloc resection and fixation.
\end{abstract}

\section{Introduction}

Giant cell tumor (GCT) is an osteolytic mass mainly affecting long bones in young adults. Sacrum accounts for 6 to $9 \%$ of all GCTs as observed in different series. ${ }^{1}$ It is rare to identify sacral GCT in early phase due to its silent nature and indolent presentation as low backache. ${ }^{1,2}$ Initially, patient is misdiagnosed and treated for low backache or lumbar spondylosis. However, imaging confirms the diagnosis, which helps in planning and improves outcome. Although histopathologically benign, these tumors are locally very aggressive. Treatment options include wide local excision/radical resection with radiotherapy (RT) versus partial excision and preservation of vital body functions. ${ }^{3,4}$ Recently, bisphosphonates, Denosumab, and interferon have also been documented for its management.

\section{Case Report}

A 30-year-old male patient presented with sudden development of bilateral lower limb weakness along with urinary

published online

November 4, 2020
DOI https://doi.org/

$10.1055 / \mathrm{s}-0040-1718856$ ISSN 0976-3147. retention. The patient was having persistent back pain and burning sensation at lumbosacral region for past 4 months. It was radiating to both the thighs in posterior aspect. Pain got aggravated during night, keeping him awake most of the time. Bowel and bladder disturbances were present. Clinical assessment revealed flaccid lower limbs. Power in both lower limbs was $2 / 5$ at all joints. The patient was unable to perform straight leg rising test. Reflexes were absent. Each rectal examination was showing large, globular, firm bulge at posterior rectal wall.

Contrast magnetic resonance imaging was done. It was showing large, well-circumscribed mass $10 \times 7 \times 7 \mathrm{~cm}$, extending from L5 to S4, suggestive of chordoma. It was also storming into the spinal canal and compressing the filum terminale at L5 level. On contrast injection, tumor was showing heterogeneous enhancement with honey comb appearance. There was blooming on susceptibility-weighted imaging suggestive of intralesional hemorrhage. Tumor was extending and pushing rectum anteriorly. It was encasing the whole filum terminale and thecal sac ( - Fig. 1A, B). On computed tomography scan, it was showing complete destruction 
of sacrum till S4 and sacroiliac joints with iliac tubercles

(-Fig. 1C). Chest X-ray was normal without any metastasis.

After consent, the patient was immediately operated. Partial en bloc resection and partial sacrectomy were done with lumboiliac fixation under intraoperative neuromonitoring. Patient positioned prone. L3, L4, and L5 pedicle screws were inserted. Both side iliac screws were inserted. L5 laminectomy was done and tumor resected from spinal canal, with thecal sac decompression done. Thecal sac was traced over the tumor using neuromonitoring and whole filum was left undisturbed over the margin of tumor. After separating filum, L5 nerve roots, and sacral nerve roots, tumor resection was attempted and around $80 \%$ tumor was delivered out. However, upper sacral nerve roots were entangled in the tumor. Tumor pieces over upper sacral nerve roots were left behind. Both S3 nerve roots were also preserved. Ilium bones were curated and posterior side of rectal wall separated from tumor. After maximal
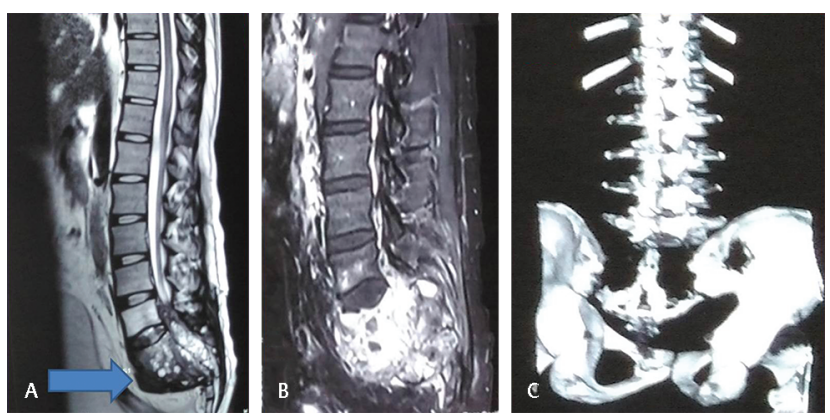

Fig. 1 (A) T2-weighted magnetic resonance imaging (sagittal) showing heterogenous mass occupying sacral region. (B) Heterogeneously enhancing mass at sacrum region. (C) Three-dimensional computed tomography of lumbosacral spine showing thinned out sacrum. tumor debulking, bone graft was placed and T-connector attached (-Fig. 2A-C). Intraoperatively, the patient required $1,500 \mathrm{~mL}$ of blood transfusion with $600 \mathrm{~mL}$ fresh frozen plasma.

Postoperatively, the patient went into aggressive physiotherapy both for lower limb and sphincters. Gradually, power came back $(4+/ 5)$ in both lower limbs within 1 week (-Fig. 2D). Mobilization on wheel chair was continued but weight bearing on both lower limbs was avoided for 3 months till the time of fusion. After 1 month of surgery, the patient received one cycle of RT and three cycles of Denosumab injection. The patient started walking after 3 months with the support of walker. He regained voluntary control of urinary bladder and anal sphincter. His sexual activity was diminished but erection was present.

Histopathology of the mass came out as GCT of sacrum. It was showing numerous large osteoclast-like giant cells with mononuclear stromal cells. Stroma was having congestive and/or hyperemic blood vessels. There was minimal nuclear pleomorphism ( - Fig. 3D).

\section{Discussion}

For GCTs of long bones, intralesional excision is considered as the treatment of choice. Intraoperatively, adjuvants like hydrogen peroxide or methyl methacrylate are also utilized after excision. It diminishes chances of local recurrence. ${ }^{5}$ However, treatment options for GCT of sacrum is quite different. Tumors at this particular area often compress filum terminale and invade transmitting and exiting spinal nerve roots; therefore, radical resection should be avoided. Additionally, adjuvants like bone cement, phenol, or cryotherapy can cause damage to nerve roots limiting
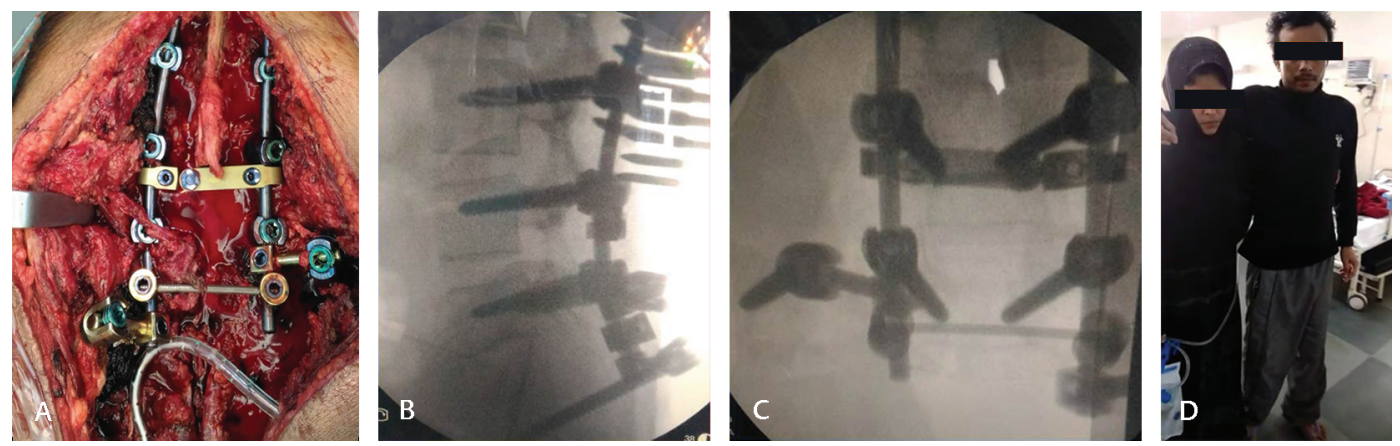

Fig. 2 (A) Intraoperative image showing lumbo-iliac fixation. (B, C) X-ray showing screw and rod with connectors in situ. (D) Postoperative photo of patient standing with support.
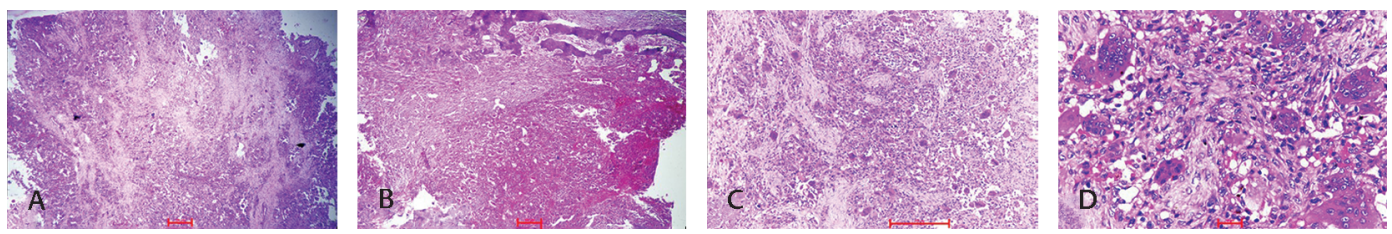

Fig. 3 (A) Tumor composed of monomorphic oval to spindle shape stromal cells along with giant cells (hematoxylin and eosin [H\&E] x40). (B) Areas of hemorrhage/vascular congestion (H\&E, x40). (C) Giant cells uniformly distributed in the stroma (H\&E, x100). (D) Minimal nuclear pleomorphism with giant cells (H\&E, x400). 
its usage. ${ }^{5,6}$ Treatment options for sacral GCT can either be invasive or noninvasive. Possible invasive options are radical surgical resection with and without internal iliac artery ligation. ${ }^{7,8}$ Complete resection versus partial resection is determined by the quality of life that patients want to live. Due to highly vascular nature, in-depth location, and huge size, it is difficult to go for gross total resection with normal free margins for GCTs. Due to encasement of multiple sacral nerve roots and engulfment of filum terminale, it is very difficult to excise the tumor without providing any disability. However, young patients should be given a chance to live disability-free life even if gross total microscopic resection is not possible. ${ }^{9}$ Although radical resection decreases the chance of local recurrences, it needs sacrifice of vital sacral nerve root with lifelong catheterization and colostomy. ${ }^{3,4,10}$ In the better interest of the patient, we performed partial en bloc resection with partial sacrectomy, leaving behind macroscopic tumors over sacral nerve roots.

Another aspect of management for sacral tumor is reconstruction and fusion after tumor resection and sacrectomy. Upper sacral segments are completely destroyed in sacral chordomas, which causes pelvic and spinal instability. ${ }^{3,40}$ Pedicle screws and iliac screws with allograft placement are major contributors in fixation and fusion. Lumbosacral fixation is enough in majority of the cases. However, if sacroiliac joints are destroyed with iliac bone, then lumboiliac fixation has to be done as in our case.

Radical resection of the GCT of the sacrum is considered as the most applicable surgical management below the S3 level. ${ }^{7}$ Leggon et al have reported $0 \%$ of local recurrence after surgical excision with wide margins. But they have achieved such results at the expense of iatrogenic nerve injury. ${ }^{10}$ Jamshidi et al have reported local recurrence in $47 \%$ of the cases. In their study, 16 patients out of 19 were having large tumors extending above S2 level. Surgically it was impossible to perform radical resection along with preservation of nerve roots. To avert bowel bladder disturbances, sexual dysfunction, paraparesis, and possible lumbopelvic disengagement, radical resection was avoided in the majority of the cases. ${ }^{5}$ Tumors distal to S2 level underwent radical resection in this series. These patients (total three) neither reported any recurrence, nor were spino-pelvic stabilization needed. ${ }^{5}$ Radical resection of GCT is only done when tumor is distal enough to avoid spinal nerve injury. Patient was young and to avoid complete bowel and bladder dysfunction, we decided to remove the tumor partial en bloc and subject him for chemotherapy and RT.

It has been suggested to do arterial embolization or bilateral iliac artery ligation to diminish intraoperative bleeding and prevent local recurrences. ${ }^{3}$ Hosalkar et al have suggested internal iliac arterial embolization with success in seven cases out of nine. ${ }^{11}$ But due to utilization of only needle biopsy, chances of diagnostic error are always there. ${ }^{11}$ As our center is not equipped with the instruments for performing serial arterial embolization, we did not use it.

Noninvasive management includes RT, zoledronic acid (bisphosphonates), and Denosumab. RT has been used for treatment since a very long time. But it has shown to be of no effect on local recurrence whether it is given alone or used as an adjuvant therapy (postsurgery). It has been reported in studies that recurrence rate is $49 \%$ after RT, $47 \%$ after surgery, and $46 \%$ after combined therapy. ${ }^{10}$ This study also revealed that large doses of radiation do not decrease the rate of local recurrence. ${ }^{10}$ Chakravarti et al have reported recurrence of sacral GCT in two out of five patients after giving RT with doses between 40 and 70 Gy. ${ }^{12}$ External beam irradiation also increases the chances of malignant transformation in sacral GCT. Utilization of intensity-modulated RT for these tumors in near future may increase success rate due to more focused targeting. ${ }^{5}$

Denosumab binds to RANKL gene and reduces the lytic features of giant cells. ${ }^{13}$ We gave our patient subcutaneous injection of Denosumab on monthly basis for 3 months. However, we were unable to continue due to high cost of the drug.

Incidence of local recurrences is $\leq 16 \%$. Pulmonary metastasis is shown in 1 to $7 \%$ of patients. ${ }^{8,14}$ Chan et al have reported pulmonary metastasis in $6.6 \%$ of cases. ${ }^{14}$ Pulmonary metastasis is common in young age, and in patients with axial GCT, recurrent GCT, and stage-3 GCT. ${ }^{14}$ After 1 year of discontinuation of the injection Denosumab, our patient presented with pulmonary metastasis and before any evaluation he went into cardiac arrest. - Table 1 shows comparison of similar cases operated by different surgeons with the present case.

\section{Conclusion}

Sacral GCT should be treated aggressively with preservation of sacral nerve roots and filum to provide disability-free life

Table 1 Comparison of various studies with our case

\begin{tabular}{|c|c|c|}
\hline Study & Treatment & Recurrence \\
\hline $\begin{array}{l}\text { Balke et al }{ }^{1} \\
\text { (19 cases) }\end{array}$ & Embolization + resection & $15 \%$ \\
\hline $\begin{array}{l}\text { Jamshidi et al }{ }^{5} \\
\text { (19 cases) }\end{array}$ & $\begin{array}{l}\text { Intralesional curettage (no } \\
\text { radiotherapy }[\mathrm{RT}] \text { ) }\end{array}$ & $47 \%$ \\
\hline $\begin{array}{l}\text { Martin and } \\
\text { McCarthy } \\
\text { ( } 23 \text { cases) }\end{array}$ & $\begin{array}{l}\text { Embolization + excision } \\
\text { En bloc resection }\end{array}$ & $\begin{array}{l}33 \% \\
15 \%\end{array}$ \\
\hline $\begin{array}{l}\text { Leggon et } \text { al }^{10} \\
\text { (17 cases) }\end{array}$ & $\begin{array}{l}\text { Wide local excision } \\
\text { RT } \\
\text { Surgery (partial excision) } \\
\text { Surgery + RT }\end{array}$ & $\begin{array}{l}0 \% \\
49 \% \\
47 \% \\
46 \% \\
\end{array}$ \\
\hline $\begin{array}{l}\text { Chakravarti et al }{ }^{12} \\
\text { (20 cases) }\end{array}$ & $\begin{array}{l}\text { RT } \\
\text { Partial resection + RT }\end{array}$ & $\begin{array}{l}15 \% \\
15 \%\end{array}$ \\
\hline Author case & $\begin{array}{l}\text { Partial en bloc resection + } \\
\text { RT + Denosumab }\end{array}$ & $\begin{array}{l}\text { Pulmonary } \\
\text { metastasis } \\
\text { after } 1 \text { year }\end{array}$ \\
\hline
\end{tabular}


to young patients. Multimodality treatment is always advised for resection and to prevent recurrence with metastasis. As neurosurgeons, our target is disability-free life with or without disease-free body.

Conflict of Interest

None declared.

\section{References}

1 Balke M, Henrichs MP, Gosheger G, et al. Giant cell tumors of the axial skeleton. Sarcoma 2012;2012. DOI: 10.1155/ 2012/410973

2 Turcotte RE, Sim FH, Unni KK. Giant cell tumor of the sacrum. Clin Orthop Relat Res 1993;(291):215-221

3 Lin PP, Guzel VB, Moura MF, et al. Long-term follow-up of patients with giant cell tumor of the sacrum treated with selective arterial embolization. Cancer 2002;95(6):1317-1325

4 Guo W, Ji T, Tang X, Yang Y. Outcome of conservative surgery for giant cell tumor of the sacrum. Spine 2009;34(10):1025-1031

5 Jamshidi K, Bagherifard A, Mirzaei A, Bahrabadi M. Giant cell tumor of the sacrum: series of 19 patients and review of the literature. Arch Bone Jt Surg 2017;5(6):443-450

6 Balke M, Schremper L, Gebert C, et al. Giant cell tumor of bone: treatment and outcome of 214 cases. J Cancer Res Clin Oncol 2008;134(9):969-978
7 Thangaraj R, Grimer RJ, Carter SR, Stirling AJ, Spilsbury J, Spooner D. Giant cell tumour of the sacrum: a suggested algorithm for treatment. Eur Spine J 2010;19(7):1189-1194

8 Martin C, McCarthy EF. Giant cell tumor of the sacrum and spine: series of 23 cases and a review of the literature. Iowa Orthop J 2010;30(1):69-75

9 Wuisman P, Lieshout O, Sugihara S, van Dijk M. Total sacrectomy and reconstruction: oncologic and functional outcome. Clin Orthop Relat Res 2000;381:192-203

10 Leggon RE, Zlotecki R, Reith J, Scarborough MT. Giant cell tumor of the pelvis and sacrum: 17 cases and analysis of the literature. Clin Orthop Relat Res 2004;(423):196-207

11 Hosalkar HS, Jones KJ, King JJ, Lackman RD. Serial arterial embolization for large sacral giant-cell tumors: mid- to long-term results. Spine 2007;32(10):1107-1115

12 Chakravarti A, Spiro IJ, Hug EB, Mankin HJ, Efird JT, Suit HD. Megavoltage radiation therapy for axial and inoperable giant-cell tumor of bone. J Bone Joint Surg Am 1999;81(11): 1566-1573

13 Roux S, Mariette X. RANK and RANKL expression in giant-cell tumour of bone. Lancet Oncol 2010;11(6):514

14 Chan CM, Adler Z, Reith JD. Gibbs CP Jr. Risk factors for pulmonary metastases from giant cell tumor of bone. J Bone Joint Surg Am 2015;97(5):420-428 